\title{
The Treatments of Twin-Twin Transfusion Syndrome in Monochorionic Twin Pregnancies by the Fetoscopic Laser Photocoagulation
}

Takeshi Murakoshi*, Hiroo Naruse, Satoru Nakayama and Yuichi Torii

Division of Perinatology, Fetal Diagnosis and Therapy, Maternal and Perinatal Care Center, Seirei Hamamatsu General Hospital, Hamamatsu, Japan

\begin{abstract}
Aims: Fetoscopic laser surgery has been widely accepted of optimal treatment for Twin-Twin Transfusion Syndrome (TTTS) in monochorionic twin pregnancies. To avoid surgical complication and to improve the outcome, various techniques employed in our institution. The aim of our study is to assess the clinical outcomes of TTTS after laser surgery with combined various techniques.
\end{abstract}

Methods: We performed 171 cases of fetoscopic laser surgery for TTTS from 2002 to 2011 in our institution. Various techniques employed in our studies to improve the learning of laser surgery and to achieve successful outcome were; (1) A very thorough mapping of vascular anastomoses before and after ablation; (2) Obliteration of arterio-venous anastomoses from donor to recipient should be done first, (3) Trocar assisted technique using gentle indent the trocar withdrawing the scope shortly, to ablate anastomoses easily, (4) A virtual line was drawn by laser at the hemodynamic equator to avoid residual anastomoses, and not to miss small anastomoses.

Results: Laser photocoagulation was performed since 2002 in our institute, compiling 171 cases. Overall survival was $78 \%$ with $5 \%$ neonatal morbidity. Both twins survived for $64 \%$, and the survival of one twin was $93 \%$. The recurrent TTTS rate was $1 \%$, and the residual vessel rate was $2 \%$.

Conclusion: A successful outcome for fetoscopic laser surgery is achievable and the outcome is improved in severe TTTS cases by these techniques.

Keywords: Twin-twin transfusion syndrome; Fetoscopy; Laser; Amnioreduction; Ultrasonography

\section{Introduction}

Fetoscopic laser surgery for severe Twin-Twin Transfusion Syndrome (TTTS) has been conducted since early 1990s in United States and Europe. After the conclusion of Eurofetus in the randomized clinical trial [1], fetoscopic laser surgery has become the standard and optimal treatment for the TTTS condition. Recently, the techniques have been implemented throughout the globe; many institutions have instituted the performance of fetoscopic laser surgery. As with many new procedures, fetoscopic laser surgery has a steep learning curve for a variety of reasons, i.e., challenging placental location, complex and unexpected communicating anastomoses, dividing membrane lifting, residual anastomoses after surgery, or discolored amniotic fluid. The laser surgery has been performed in Japan since 2002, and five laser centers employ the same protocols. More than 700 TTTS cases, 180 cases were treated by laser surgery to date in our institution. The new technical tips to improve the achievement of successful outcome will be introduced and reviewed for laser surgery and our data of perinatal outcome and complication of fetoscopic laser surgery for severe TTTS will be indicated in this article.

\section{Pathophysiology and diagnosis of TTTS}

Because of vascular anastomoses between the fetuses, monochorionic twin pregnancies have a high-risk profile compared with dichorionic twin pregnancies. TTTS is one of the major complications resulting from vascular anastomoses and their imbalanced blood distribution in about $5-10 \%$ of monochorionic twins. TTTS can be characterized by an imbalanced blood distribution, due to a net flow from one fetus (the donor twin) to the other (the recipient twin) through placental communicating vessels. The donor twin is characterized by a hypodynamic status, manifested by hypovolemia, hypotension, oliguria, oligohydramnios, fetal growth restriction, and renal failure.
These processes ultimately result in fetal demise. In contrast, the recipient twin is characterized by a hyperdynamic status, hypervolemia, hypertension, polyuria, polyhydramnios, heart failure, and hydrops fetalis; thus it often also results in a fetal demise. The prognosis for severe early onset TTTS is dismal, with perinatal mortality rates of up to $90 \%$ if untreated.

TTTS is defined prenatally by ultrasonography as: a monochorionic diamniotic twin pregnancy; polyuric polyhydramnios in the recipient twin (maximum vertical pocket $>8 \mathrm{~cm}$, and large distended bladder) with oliguric oligohydramnios in the donor twin (maximum vertical pocket $<2 \mathrm{~cm}$ and collapsed or non-visible bladder) simultaneously; and no signs of abnormality due to poly- or oligo-hydramnios. Once the diagnosis of TTTS is made, the severity is classified by Quintero's stage [2] from I to V. Stage III TTTS is sub-classified into two sub-groups defined by whether the donor bladder is visible or non-visible. Subclassification of Stage III $[2,3]$ is defined as follows: Stage III classical (Doppler studies are critically abnormal in either twin and the bladder of the donor is not visible); and Stage III atypical (Doppler studies are critically abnormal in either twin and the bladder of the donor is still visible).

*Corresponding author: Takeshi Murakoshi, Division of Perinatology, Feta Diagnosis and Therapy, Maternal and Perinatal Care Center, Seirei Hamamatsu General Hospital, 1-12-12 Sumiyoshi, Hamamatsu, 430-8558, Japan, Tel: +81-53474-2222; Fax: +81-53-475-7596; E-mail: t-murakoshi@sis.seirei.or.jp

Received March 14, 2013; Accepted April 18, 2013; Published April 24, 2013

Citation: Murakoshi T, Naruse H, Nakayama S, Torii Y (2013) The Treatments of Twin-Twin Transfusion Syndrome in Monochorionic Twin Pregnancies by the Fetoscopic Laser Photocoagulation. J Health Med Informat S11: 005. doi:10.4172/2157-7420.S11-005

Copyright: (c) 2013 Murakoshi T, et al. This is an open-access article distributed under the terms of the Creative Commons Attribution License, which permits unrestricted use, distribution, and reproduction in any medium, provided the original author and source are credited. 


\section{Methods and Subjects}

\section{Concept of fetoscopic laser surgery for TTTS}

Fetoscopic laser surgery of communicating vessels for severe TTTS consists of a few basic principles: in as much as imbalanced blood distribution due to placental vascular anastomoses are thought to be the main cause of TTTS, laser ablation of communicating vessels can eliminate the cause of TTTS; and all anastomoses (AV (ArterioVenous), AA (Arterio-Arterial), VV (Veno-Venous Anastomoses) can be visualized and ablated by a fetoscopic procedure.

\section{Preparation for fetoscopic laser surgery}

Essentially, before attempting the procedure, operators should be knowledgeable of the complex pathophysiology of TTTS and other TTTS-related events such as Twin Anemia Polycythemia Sequence (TAPS), acute feto-fetal hemorrhage after single fetal demise, Selective Intrauterine Growth Restriction (sIUGR) in monochorionic twin, and Twin Reversed Arterial Perfusion (TRAP) sequence. Ultrasound assessment should be conducted and the echocardiographic features of TTTS must be evaluated. The donor twin is characterized by a hypovolemic status of the placenta and circulatory insufficiency. Fetal growth restriction and umbilical arterial Doppler abnormalities are common ultrasound features. Doppler examination reveals a decrease in the end-diastolic velocity of the umbilical artery, especially the absence or reverse end-diastolic velocity in Stage III or IV. Decreased peak systolic velocities of the descending aorta are also common. Coarctation of the aorta in the donor or smaller fetus in a monochorionic twin pregnancy has been reported and, based on the hemodynamic theory, decreased blood flow into the donor or smaller twin might increase the risk of a coarctation of the aorta [4]. Most recipient fetuses develop cardiac dysfunction complicated by cardiomegaly, tricuspid and mitral valve regurgitation, ventricular hypertrophy, increased reverse flow in the inferior vena cava, and pulmonary stenosis; they also develop reverse flow of the ductus venosus and pulsatile flow in the umbilical vein $[5,6]$. Typically, mild cardiomegaly and increased reverse flow in the inferior vena cava occurs first; moreover, right ventricle compromise occurs earlier than left ventricle. Congestive heart failure and hydrops fetalis in the recipient may originate from chronic volume and pressure overload of the right ventricle. These conditions lead to cardiomegaly and atrioventricular valve regurgitation. Occasionally, some cases of a severely affected recipient can develop into acquired pulmonary stenosis/atresia with an intact ventricular septum [5,7].

Additionally, the operator should be trained to identify and characterize the vascular anastomoses of the monochorionic placenta. Placental dye injection examination [8,9] of the monochorionic placenta should be an important step before attempting laser surgery (Figure 1). All vessels on the placental surface can be precisely differentiated by fetoscopic inspection; arteries principally cross over veins and the color of arteries is dark blue due to deoxygenated blood, whereas veins appear bright red due to oxygenated blood from the placenta. AA and $\mathrm{VV}$ anastomoses are directly linked artery-to-artery or vein-to-vein, and have no terminal ends. While AV anastomosis is not anatomical anastomosis itself, the artery (feeding artery) comes from a fetus to cotyledon, and goes to the other fetus as drainage vein. It is called an $\mathrm{AV}$ anastomosis. Occasionally, three or four vessels cotyledons are seen, in which three or four types of different vessels are in to same cotyledon. AA anastomoses are theoretically complex and bidirectional transfusion depends on the location of the hemodynamic equator and branch of artery. This mechanism can provide AA anastomoses as

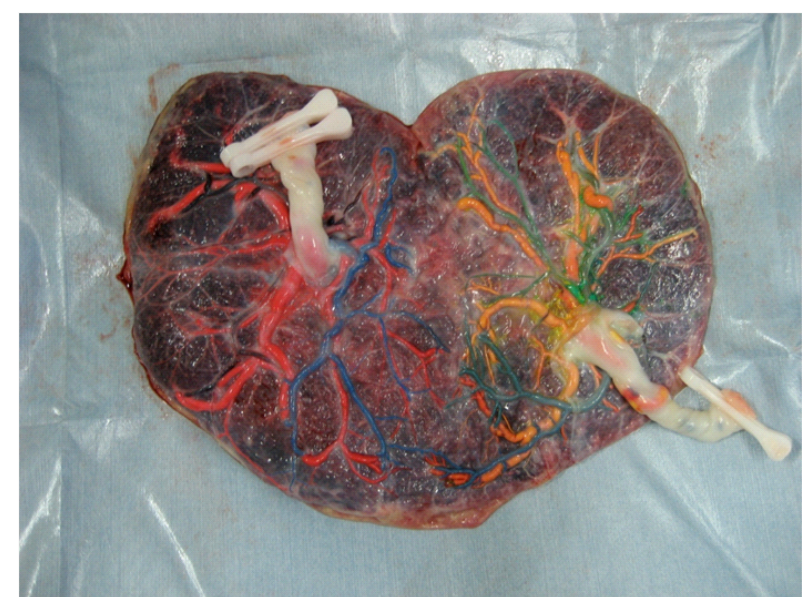

Figure 1: Dye injections into vessels of monochorionic placenta after delivery

functional AV behavior for both directions [10]. Blue or green dye was injected into the artery, and red or yellow dye into the vein.

\section{Setting and performance of fetoscopic laser surgery (Procedural steps)}

Epidural anesthesia or local anesthesia with maternal conscious sedation can be chosen for fetoscopic laser surgery. In our first 36 cases, general anesthesia was chosen; this option was similar to that of other institutions in the early period of fetoscopic laser surgery because immobility of the fetuses especially in the recipient fetus; however after operator skills improved, epidural or local anesthesia were chosen because they were less invasive for the mother and could decrease maternal complications [11]. After adequate anesthesia was achieved, a $3.8 \mathrm{~mm}$ trocar (Richard Wolf, Vernon Hills, IL, USA) was inserted into the recipient amniotic sac with ultrasonographic guidance. Appropriate fetoscopes (i.e., Richard Wolf angled-view endoscope, 2.8 $\mathrm{mm}$ diameter, $30 \mathrm{~cm}$ length; 25 degree (RW-8930.402), 30 degree (RW8930.422), 70 degree (RW-8660.412), operative 12 degree with working channel for $5 \mathrm{Fr}$ instruments (RW-8746.401); and a $2 \mathrm{~mm}$ diameter, $26 \mathrm{~cm}, 0$ degree rigid telescope (K26008AA, Karl Storz, Tuttlingen, Germany) with sheath $(\mathrm{K} 11630 \mathrm{KH})$ ) were selected according to the placental and fetal location. All communicating vessels were initially mapped and then ablated by Neodymium:Yttrium-Aluminium-Garnet (Nd:YAG) laser (Surgical Laser Technology, Montgomery, PA); this was conducted via the non-contact method with fetoscopic guidance. Laser fibers were inserted into the operating channel of the fetoscope and the laser power was usually set from 15 to 40 watts for Nd:YAG $(1,064 \mathrm{~nm})$ laser. Re-examination and re-lasering of anastomoses with mapping was then done; subsequently, the hemodynamic equator was drawn by laser. Finally, amnio drainage was done if indicated.

\section{Mapping system}

During the procedure, placental vessel mapping helps the operator to identify and orient the direction and location the anastomoses. Before laser ablation, a very thorough mapping of vascular anastomoses must be done by the operator and navigator. Each vascular anastomosis was labeled as AV-DR, AV-RD, AA, or VV (for example, AV-DR represented an arterio-venous anastomosis from donor to recipient); the navigator records this information as figures or comments. During the laser ablation, the operator eliminates each anastomosis by referring to the mapping system. After ablation, reevaluation of all placental 
anastomoses should be done. Additionally, by using the mapping system before ablation, we can choose an appropriate sequence for the ablations.

This system also has the potential to reduce the incidence of residual anastomoses and recurrence of TTTS. A low incidence of residual anastomoses and recurrence of TTTS was reported by Cincotta et al. [12], Chmait et al. [13] and our series [3]; all three studies employed a mapping system.

\section{Sequential order}

Quintero et al. [14] and Nakata et al. [15] proposed the new technique that all anastomoses should be ablated in a specific order to reduce the incidence of a fetal demise after laser surgery, especially a donor with the loss of or reversed umbilical arterial flow: first, AV-DRs; then, AV-RDs. In particular, the donor twin with an abnormal Doppler of the umbilical artery appears logically to be more vulnerable to an acute hemodynamic change such as hypotension or anemia. If AVRDs are obliterated first, inter twin transfusion from donor to recipient occurs; thus, the donor twin develops increased hypotension and anemia followed by fetal demise. Sequential laser ablation of anastomoses and elimination of the AVDRs prior to the AVRDs could result in improved blood pressure of the donor via an intraoperative inter twin transfusion, rescue as well as stabilization of the hemodynamics of the donor. It is currently controversial whether arterio-arterial and venovenous anastomoses should ablated first, prior to $\mathrm{AV}$ anastomoses, or last; however, an AVDR first policy could reduce fetal demise after laser surgery especially in donors with abnormal Doppler [14,15]. The US Fetus Consortium is currently undergoing a randomized control trial to compare outcomes between the standard laser approach and the sequential laser approach.

\section{Trocar assisted techniques in anterior placenta}

An anterior placenta is the most difficult settings for FLP, i.e., it becomes quite difficult to confirm the anastomoses and to ablate the vessels, because of the tangential angle of target vessels and fetoscope alignment. Quintero et al. [16] originally proposed the technique of trocar-assisted selective laser photocoagulation. The rigid trocar is gently inserted behind the anteriorly located placenta by withdrawing the scope within the trocar a short distance, where the angle is adequate to ablate the vessels, as it is perpendicular by the technique, pushing the trocar close to the target vessel. At this point, the anastomoses can be easily ablated because the target vessel and fetoscope are perpendicular rather than tangential. The trocar-assisted technique has three benefits: (1) It allows perpendicular rather than tangential alignment of the target vessels; (2) Reduction of the blood flow in large communicating vessels (Figure 2). The pressure exerted by the trocar reduces the flow and allows for ablation with less laser energy; and (3) the technique is possible to avoid inadvertent injury to the fetus and dividing membrane for safe ablation of the target vessels. One type of fetoscope can be used without the trocar, i.e., an appropriate fetoscope can be selected, i.e., 0 degree, 30 degree, or 70 degree is selected for an anterior placenta. Furthermore, both Richard Wolf and Karl Storz instruments fit a 3.8 mm cannula.

The rigid trocar is gently inserted behind the anteriorly located placenta withdrawing the fetoscope in the trocar for a short distance. The perpendicular angle is adequate to ablate the vessels after the trocar assisted technique.

\section{Line drawing methods}

A virtual line should be drawn with the laser at the hemodynamic

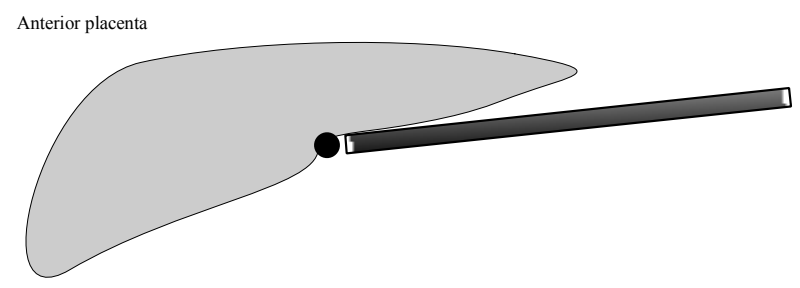

Figure 2: Trocar assisted technique.

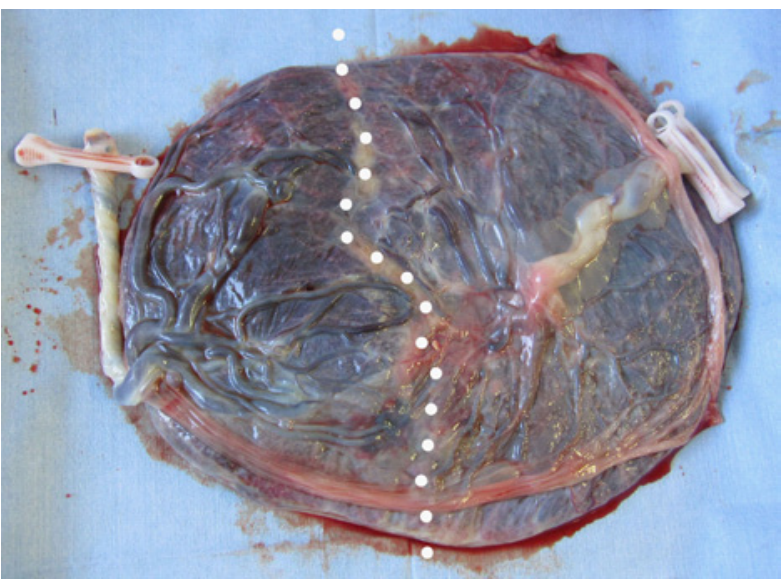

Figure 3: Line drawing method

equator, but not the membrane equator, to avoid residual anastomoses (Figure 2). The technique is also reported as the Solomon technique; which is a trial currently ongoing to test this method in Europe (www. trialregister.nl, trial ID: NTR1245). Small anastomoses are not missed by the virtual line method. First, selective laser ablation is performed to avoid residual anastomoses at each vascular end of anastomotic vessels and to avoid residual anastomoses. Second, the technique constructs a dotted line with the laser; and finally forms a virtual line with the laser along the hemodynamic equator (Figure 3 ). The technique draws the doted line with laser ablation along with the hemodynamic equator, creating the dichorionized placenta.

\section{TTTS patients}

One hundred and fifty two Japanese women whose pregnancy was complicated by severe TTTS before 26 weeks of gestation underwent fetoscopic laser surgery in our institution in the years from 2002 to 2011. All patients were delivered and their infants were followed-up for at least six months. TTTS was diagnosed in monochorionic twin pregnancies based on standard ultrasound criteria: polyhydramnios and oligohydramnios with the deepest vertical amniotic pocket measuring at least $8.0 \mathrm{~cm}$ in the recipient and at most $2.0 \mathrm{~cm}$ in the donor. All patients met the following criteria for laser surgery: gestational age less than 26 weeks; and Quintero's stage classification was I to IV. The laser procedure for placental communicating vessels was based on a previously reported method [3] with additional techniques described above if indicated: mapping system; sequential order of AV-DR first policy if possible; using a trocar of appropriate diameter for the fetoscope; employing trocar-assisted technique and laser line drawing methodology. Patient baseline and surgical characteristics are presented in (Table 1). Sixty eight percent of the patients were stage III (54\%) and IV (14\%), and $51 \%$ of the patients had an anterior placenta. 


\begin{tabular}{|l|l|}
\hline Maternal Age (year) & $30(15-42)$ \\
\hline Gestational age at surgery (weeks) & $21(16-25)$ \\
\hline Location of placenta & \\
\hline Anterior & $87(51 \%)$ \\
\hline Posterior & $84(49 \%)$ \\
\hline Quintero stage & $19(11 \%)$ \\
\hline Stage I & $36(21 \%)$ \\
\hline Stage II & $92(54 \%)$ \\
\hline Stage III & 31 \\
\hline atypical & 61 \\
\hline classical & $24(14 \%)$ \\
\hline Stage IV & $170(99 \%)$ \\
\hline Complete surgery & \\
\hline Anesthesia & $36(21 \%)$ \\
\hline General & $135(79 \%)$ \\
\hline Epidural & $58(24-158)$ \\
\hline Operation time (minutes) &
\end{tabular}

Data are shown as median (range) or number (\%)

Table 1: Baseline and surgical characteristics $(n=171)$.

\begin{tabular}{|l|l|}
\hline Gestational age at delivery (weeks) & $33(19-40)$ \\
\hline Miscarriage (delivery<22 weeks) & $6(3.5 \%)$ \\
\hline Recurrent TTTS & $1(0.6 \%)$ \\
\hline TAPS & $2(1.2 \%)$ \\
\hline Residual anastomoses & $4(2.4 \%)$ \\
\hline Overall survival $(\mathrm{n}=342)$ & $267 / 342(78 \%)$ \\
\hline Neurological sequels $(\mathrm{n}=267)$ & $13 / 267(4.9 \%)$ \\
\hline 2 survivors & $110(64 \%)$ \\
\hline 1 survivor & $49(29 \%)$ \\
\hline 0 survivor & $12(7 \%)$ \\
\hline At least 1 survivor & $159(93 \%)$ \\
\hline
\end{tabular}

Data are shown as median (range) or number (\%)

Table 2: Pregnancy outcome and survival rates $(n=171)$.

\begin{tabular}{|l|l|l|l|l|l|}
\hline Stage & $\begin{array}{l}\text { I } \\
\mathbf{n = 1 9}\end{array}$ & $\begin{array}{l}\text { II } \\
\mathbf{n = 3 6}\end{array}$ & $\begin{array}{l}\text { II atypical } \\
\mathbf{n = 3 1}\end{array}$ & $\begin{array}{l}\text { III classical } \\
\mathbf{n = 6 1}\end{array}$ & $\begin{array}{l}\text { IV } \\
\mathbf{n = 2 4}\end{array}$ \\
\hline 2 survivors & $13(69 \%)$ & $26(72 \%)$ & $14(45 \%)$ & $42(69 \%)$ & $15(67 \%)$ \\
\hline 1 survivor & $5(26 \%)$ & $6(17 \%)$ & $15(48 \%)$ & $14(23 \%)$ & $9(33 \%)$ \\
\hline 0 survivor & $1(5 \%)$ & $4(11 \%)$ & $2(7 \%)$ & $5(8 \%)$ & $0(0 \%)$ \\
\hline $\begin{array}{l}\text { At least 1 } \\
\text { survivor }\end{array}$ & $18(95 \%)$ & $32(89 \%)$ & $29(93 \%)$ & $56(92 \%)$ & $24(100 \%)$ \\
\hline $\begin{array}{l}\text { Overall } \\
\text { survival }\end{array}$ & $31 / 38(82 \%)$ & $58 / 72(81 \%)$ & $43 / 62(69 \%)$ & $98 / 122(80 \%)$ & $39 / 48(81 \%)$ \\
\hline $\begin{array}{l}\text { Neurological } \\
\text { sequels }\end{array}$ & $1 / 31(3.2 \%)$ & $4 / 58(6.9 \%)$ & $3 / 43(6.9 \%)$ & $2 / 98(2.0 \%)$ & $3 / 39(7.7 \%)$ \\
\hline
\end{tabular}

Data are shown as number (\%)

Table 3: Perinatal outcome according to Quintero stage.

\section{Results}

We completed laser surgery on $99 \%$ of the patients. The median surgical time was 58 minutes; however, surgical time was counted from the insertion of the trocar to amino drainage with the following intervening steps: fetoscopic inspection, mapping, and laser ablation. (Tables 2 and 3) present the perinatal outcomes. The overall survival rate was $78 \%$; and $4.9 \%$ of the cases had neurological sequels including periventricular leukomalacia, intraventricular hemorrhage grade 3 and 4 , and cerebral palsy. At six months after delivery: in $64 \%$ of the cases, twins survived; in $29 \%$ of the cases, one twin survived; and in $93 \%$ of the cases at least one twin survived. The Quintero stage did not worsen in any of the survivors; however, stage III atypical, which was defined

\begin{tabular}{|c|c|c|c|c|c|c|c|c|c|c|}
\hline & \begin{tabular}{|l|} 
Ville \\
et al. \\
{$[19]$} \\
$n=132$ \\
\end{tabular} & \begin{tabular}{|l} 
Hetcher \\
etal. \\
{$[17]$} \\
$n=73$
\end{tabular} & \begin{tabular}{|l} 
Hetcher \\
et al. \\
{$[20]$} \\
$n=200$
\end{tabular} & \begin{tabular}{|l|} 
Quintero \\
et al. \\
{$[10,18]$} \\
$n=95$ \\
\end{tabular} & \begin{tabular}{|l|} 
Senat \\
et al. \\
{$[1]$} \\
$n=72$ \\
\end{tabular} & \begin{tabular}{|l|} 
Huber \\
et al. \\
{$[22]$} \\
$n=200$ \\
\end{tabular} & \begin{tabular}{|l} 
Middledorp \\
et al. \\
2007 \\
$n=100$
\end{tabular} & $\begin{array}{l}\text { Cincotta } \\
\text { et al. } \\
{[12]} \\
n=100\end{array}$ & \begin{tabular}{|l|} 
Chmait \\
et al. \\
{$[23]$} \\
$n=682$
\end{tabular} & \begin{tabular}{|l|} 
Present \\
study \\
2012 \\
$n=171$
\end{tabular} \\
\hline $\begin{array}{l}\text { Median } \\
\text { gestational } \\
\text { age at } \\
\text { delivery } \\
\text { (weeks) }\end{array}$ & - & 33 & 34 & 32 & 33 & 34 & 33 & 31 & 33 & 33 \\
\hline $\begin{array}{l}\text { Perinatal } \\
\text { survival (\%) }\end{array}$ & 55 & 61 & - & 64 & 56 & 72 & 70 & 76 & 79 & 78 \\
\hline $\begin{array}{l}\text { Neurological } \\
\text { sequels (\%) }\end{array}$ & 4 & 6 & 6 & 4 & 7 & - & - & 3 & & 5 \\
\hline $\begin{array}{l}2 \text { survivors } \\
(\%)\end{array}$ & 36 & 42 & 50 & 44 & 36 & 60 & 58 & 66 & 72 & 64 \\
\hline $\begin{array}{l}1 \text { survivor } \\
(\%)\end{array}$ & 38 & 37 & 30 & 38 & 38 & 24 & 23 & 19 & 18 & 29 \\
\hline $\begin{array}{l}0 \text { survivor } \\
(\%)\end{array}$ & 26 & 21 & 20 & 17 & 26 & 17 & 19 & 15 & 10 & 7 \\
\hline $\begin{array}{l}\text { At least } 1 \\
\text { survivor }\end{array}$ & 74 & 79 & 80 & 82 & 74 & 84 & 81 & 85 & 90 & 93 \\
\hline
\end{tabular}

Table 4: Comparison of perinatal outcomes in published series.

as abnormal Doppler flow with visible donor bladder, had a decreased survival rate especially in 2 survivors.

\section{Discussion}

Table 4 presents the perinatal outcomes in published series including early series of pioneer operators $[1,17-20]$ and published data [12,21-24] from the conclusion of the Eurofetus trial comparing to the present study. Early series reported approximately a $60 \%$ overall survival rate, a $5 \%$ neurological complication rate; and a $40 \%$ survival rate of both twins. Middledorp et al. [21], Cincotta et al. [12], Huber et al. [22], and Chmait et al. [23] describe improved perinatal outcomes: $>70 \%$ overall survival, $58-69 \%$ with two survivors and; $>80 \%$ with at least one survivor. Hecher et al. [20] and Huber et al. [22] reported the data from their 400 consecutive case series divided into two groups: the first 200 and last 20. As their experience increased, they reported an increasing overall survival rate, especially for cases of two survivors. In our series, the overall perinatal survival for at least six months was $78 \%$; the neurological complication rate was $5 \%$; the rate for both twins surviving was $64 \%$; and at least one twin survived in $93 \%$ of the cases. These data appear favorable and are comparable to that of the latest 200 case series of Huber et al. [22]. We attribute our favorable results to mapping, trocar assisted techniques, selection of the appropriate fetoscope, sequential order ablation, and the laser line drawing method. Neurological sequels were periventricular leukomalasia, interaventricular hemorrhage grade III and IV and cerebral palsy.

\section{Conclusion}

In view of our experience regarding the management of TTTS, comprehensive techniques including preparation of various new devices, selection of instruments, and advanced laser ablation techniques have contributed to the progress of fetoscopic laser surgery for TTTS in monochorionic twins.

\section{Acknowledgement}

Authors express sincere gratitude to the members of Seirei Hamamatsu general hospital, particularly for the supports of Drs. M Matsushita, T Shinno, T Arakaki, and T Mishima.

\section{References}

1. Senat MV, Deprest J, Boulvain M, Paupe A, Winer N, et al. (2004) Endoscopic laser surgery versus serial amnioreduction for severe twin-to-twin transfusion syndrome. N Engl J Med 351: 136-144. 
Citation: Murakoshi T, Naruse H, Nakayama S, Torii Y (2013) The Treatments of Twin-Twin Transfusion Syndrome in Monochorionic Twin Pregnancies by the Fetoscopic Laser Photocoagulation. J Health Med Informat S11: 005. doi:10.4172/2157-7420.S11-005

2. Quintero RA, Morales WJ, Allen MH, Bornick PW, Johnson PK et al. (1999) Staging of twin-twin transfusion syndrome. J Perinatol 19: 550-555.

3. Murakoshi T, Ishii K, Nakata M, Sago H, Hayashi S, et al. (2008) Validation of Quintero stage III sub-classification for twin-twin transfusion syndrome based on visibility of donor bladder: characteristic differences in pathophysiology and prognosis. Ultrasound Obstet Gynecol 32: 813-818.

4. Yasuda K, Ohki S, Seguchi M (2004) Co-occurrence of coarctation of the aorta and hypospadias in smaller twins in monochorionic pregnancies: two case reports. Am J Perinatol 21: 131-134.

5. Murakoshi T, Yamamori K, Tojo Y, Naruse H, Seguchi M, et al. (2000) Pulmonary stenosis in recipient twins in twin-to-twin transfusion syndrome: Report on 3 cases and review of literature. Croat Med J 41: 252-256.

6. Zosmer N, Bajoria R, Weiner E, Rigby M, Vaughan J, et al. (1994) Clinical and echographic features of in utero cardiac dysfunction in the recipient twin in twintwin transfusion syndrome. Br Heart J 72: 74-79.

7. Lougheed J, Sinclair BG, Fung Kee Fung K, Bigras JL, Ryan G, et al. (2001) Acquired right ventricular outflow tract obstruction in the recipient twin in twintwin transfusion syndrome. J Am Coll Cardiol 38: 1533-1538.

8. Bajoria R, Wigglesworth J, Fisk NM (1995) Angioarchitecture of monochorionic placentas in relation to the twin-twin transfusion syndrome. Am J Obstet Gynecol 172: 856-863.

9. Lopriore E, Middeldorp JM, Oepkes D, Klumper FJ, Walther FJ, et al. (2007) Residual anastomoses after fetoscopic laser surgery in twin-to-twin transfusion syndrome: frequency, associated risks and outcome. Placenta 28: 204-208.

10. Murakoshi T, Quintero RA, Bornick PW, Allen MH (2003) In vivo endoscopic assessment of arterioarterial anastomoses: insight into their hemodynamic function. J Matern Fetal Neonatal Med 14: 247-255.

11. Rossi AC, Kaufman MA, Bornick PW, Quintero RA (2008) General vs local anesthesia for the percutaneous laser treatment of twin-twin transfusion syndrome. Am J Obstet Gynecol 199: 137.e1-e7.

12. Cincotta RB, Gray PH, Gardener G, Soong B, Chan FY (2009) Selective fetoscopic laser ablation in 100 consecutive pregnancies with severe twin-twin transfusion syndrome. Aust N Z J Obstet Gynaecol 49: 22-27.

13. Chmait RH, Assaf SA, Benirschke K (2010) Residual vascular communications in twin-twin transfusion syndrome treated with sequential laser surgery: frequency and clinical implications. Placenta 31: 611-614.
14. Quintero RA, Ishii K, Chmait RH, Bornick PW, Allen MH, et al. (2007) Sequential selective laser photocoagulation of communicating vessels in twintwin transfusion syndrome. J Matern Fetal Neonatal Med 20: 763-768.

15. Nakata M, Murakoshi T, Sago H, Ishii K, Takahashi Y, et al. (2009) Modified sequential laser photocoagulation of placental communicating vessels for twintwin transfusion syndrome to prevent fetal demise of the donor twin. J Obstet Gynaecol Res 35: 640-647.

16. Quintero RA, Chmait RH, Bornick PW, Kontopoulos EV (2010) Trocar-assisted selective laser photocoagulation of communicating vessels: a technique for the laser treatment of patients with twin-twin transfusion syndrome with inaccessible anterior placentas. J Matern Fetal Neonatal Med 23: 330-334.

17. Hecher K, Plath H, Bregenzer T, Hansmann M, Hackeloer BJ (1999) Endoscopic laser surgery versus serial amniocenteses in the treatment of severe twin-twin transfusion syndrome. Am J Obstet Gynecol 180: 717-724.

18. Quintero RA, Dickinson JE, Morales WJ, Bornick PW, Bermudez C, et al. (2003) Stage-based treatment of twin-twin transfusion syndrome. Am J Obstet Gynecol 188: 1333-1340.

19. Ville Y, Hecher K, Gagnon A, Sebire N, Hyett J, et al. (1998) Endoscopic laser coagulation in the management of severe twin-to-twin transfusion syndrome. $\mathrm{Br}$ J Obstet Gynaecol 105: 446-453.

20. Hecher K, Diehl W, Zikulnig L, Vetter M, Hackeloer BJ (2000) Endoscopic lase coagulation of placental anastomoses in 200 pregnancies with severe mid trimester twin-to-twin transfusion syndrome. Eur J Obstet Gynecol Reprod Bio 92: 135-139.

21. Middeldorp JM, Sueters M, Lopriore E, Klumper FJ, Oepkes D, et al. (2007) Fetoscopic laser surgery in 100 pregnancies with severe twin-to-twin transfusion syndrome in the Netherlands. Fetal Diagn Ther 22: 190-194.

22. Huber A, Diehl W, Bregenzer T, Hackeloer BJ, Hecher K (2006) Stagerelated outcome in twin-twin transfusion syndrome treated by fetoscopic lase coagulation. Obstet Gynecol 108: 333-337.

23. Chmait RH, Kontopoulos EV, Korst LM, Llanes A, Petisco I, et al. (2011) Stagebased outcomes of 682 consecutive cases of twin-twin transfusion syndrome treated with laser surgery: the USFetus experience. Am J Obstet Gynecol 204: 393 e1-e6.

24. Sago H, Hayashi S, Saito M, Hasegawa H, Kawamoto H, et al. (2010) The outcome and prognostic factors of twin-twin transfusion syndrome following fetoscopic laser surgery. Prenat Diagn 30: 1185-1191. 